\title{
MENGIDENTIFIKASI BEBERAPA VARIETAS TANAMAN STROBERI BERSAMA PETANI DI KECAMATAN PASIRJAMBU KABUPATEN BANDUNG
}

\section{IDENTIFY SEVERAL PLANT VARIETIES OF PLANTS WITH FARMERS IN PASIRJAMBU DISTRICT, BANDUNG DISTRICT}

\author{
N Sondari'1a, L Amalia1 , S Aminah' \\ 1Program Studi Agroteknologi, Fakultas Pertanian Universitas Winaya Mukti, Indonesia \\ a Korespondensi: Nunung Sondari; E-mail: nunungsondari@gmail.com \\ (Diterima: 30-08-2019; Ditelaah: 02-09-2019; Disetujui: 25-10-2019)
}

\begin{abstract}
Local varieties of strawberries generally have the advantage of a fragrant fruit aroma but the fruit production is small because of the small fruit size. Farmers have left local varieties because introduced varieties have the advantage in production and larger fruit sizes but have less fruit aroma compared to local ones. The purpose of exploration is to collect genetic diversity of strawberry plasmanutfah in the existing Pasirjambu District, hoping to be netted by new alleles or derived from new mutants arising from cultivars that are released to farmers. The emergence of new genotypes due to the process of evaluation, mutation, natural hybridization, and natural selection results in the emergence of new genotypes that are superior in the sense of being able to adapt to the environment. Furthermore, identification is carried out as a process of introducing plants to find out the types of plants in detail and in full and can be scientifically justified. Collecting information on biological/genetic characteristics can make it easier to obtain genotypes as a source of parent material to get new high yielding varieties.
\end{abstract}

Keywords: Identification, varieties, strawberries

\begin{abstract}
ABSTRAK
Stroberi varietas lokal umumnya memiliki keunggulan aroma buah yang harum tetapi produksi buahnya sedikit karena ukuran buahnya kecil. Petani telah meninggalkan varietas lokal karena varietas introduksi memiliki keunggulan pada produksi dan ukuran buah yang lebih besar akan tetapi memiliki aroma buah yang kurang dibandingkan dengan lokal. Tujuan eksplorasi adalah untuk menghimpun keragaman genetik plasmanutfah stroberi di Kecamatan Pasirjambu yang sudah ada, berharap terjaring alel-alel baru atau berasal dari mutan-mutan baru yang muncul dari kultivar yang dilepas ke petani. Munculnya genotip baru akibat proses evaluasi, mutasi, hibridisasi alami, dan seleksi alami mengakibatkan munculnya genotip baru yang unggul dalam arti mampu beradaptasi terhadap lingkungan. Selanjutnya dilakukan identifikasi sebagai suatu proses pengenalan tanaman untuk mengetahui jenis tanaman secara detail dan lengkap serta dapat dipertanggugjawabkan secara ilmiah. Pengumpulan informasi karakteristik biologi/genetik dapat mempermudah dalam mendapatkan genotip-genotip sebagai sumber bahan tetua untuk mendapatkan varietas unggul baru.

Kata Kunci : Identifikasi, varietas, stroberi.
\end{abstract}


Sondari, N., Amalia, L., Mukyana, H., \& Agusta, E. N. (2020). Mengidentifikasi Beberapa Varietas

Tanaman Stoberi bersama Petani di Kecamatan Pasir Jambu Kabupaten Bandung. Jurnal Qardhul Hasan: Media Pengabdian kepada Masyarakat, 6(1), 16-21.

\section{PENDAHULUAN}

Tanaman stroberi (Fragaria xananassa Duch) merupakan tanaman buah dengan daya pikat pada buahnya yang berwarna merah mencolok dan rasanya yang manis dan segar (Gunawan, 2000). Stroberi merupakan buah yang disukai oleh konsumen dan bernilai jual tinggi (Rizki Ramadani Dwi Utami dkk., 2018; Mohammad Affan Fajar Falah, dkk., 2018; serta I Gusti Ayu Devi Valenia Sari, Gusti Ngurah Alit Susanta Wurya dan I Putu Sudiarta, 2018). Stroberi di Indonesia memiliki peluang bisnis yang besar karena stroberi ini dapat dikonsumsi secara segar maupun diolah menjadi berbagai jenis bahan makanan seperti sirup, jeli, dodol, selai, jus, manisan, dan eskrim. Beberapa varietas produk olahan ini antara lain varietas Nenas dan Benggala yang sering disebut varietas lokal. Varietas lokal adalah varietas yang telah ada dan dibudidayakan oleh petani dalam kurun waktu yang lama secara terus menerus dan telah menjadi milik masyarakat serta dikuasai Negara. Varietas lokal memiliki daya adaptasi tinggi terhadap lingkungan. Perbedaan keunggulan antara varietas lokal dan introduksi yang sangat jauh dalam hal bobot buah tanaman mungkin disebabkan oleh translokasi fotosintat. Kualitas stroberi yang baik masih sulit didapatkan di level petani dengan kondisi lingkungan tropis (Mohammad Affan Fajar Falah, dkk., 2018). Lingkungan tropis mempecepat penurunan kualitas dan umur simpan produk stroberi segar.

\section{LANDASAN TEORI}

Eksplorasi merupakan kegiatan pencarian bahan-bahan genetik tanaman berupa genotip-genotip, kultivar, klon tanaman, dari alam seperti pertanaman yang ada pada petani atau dari koleksi laboratorium atau perorangan. Tujuan suatu eksplorasi plasma nutfah ialah untuk menghimpun keragaman koleksi plasma nutfah yang sudah ada. Dalam setiap eksplorasi kita berharap akan terjaring alel-alel baru yang belum terdapat dalam koleksi plasma nutfah. Alel-alel baru ini dapat berasal dari tanaman yang selama ini belum terwakili dalam koleksi plasma nutfah kita, atau berasal dari mutan-mutan baru yang muncul dari kultivar-kultivar yang pernah dilepas ke petani.

Selanjutnya perlu dilakukan identifikasi (inventarisasi dan evaluasi), sifat-sifat morfologi tanaman yang diidentifikasi berdasarkan tabel UPOV.

\section{MATERI DAN METODE}

FGD (Focus Group Discussion) dan budidaya stroberi dilaksanakan di Desa Sugih Mukti, Kecamatan Pasir Jambu, Kabupaten Bandung dengan ketinggian tempat $1200 \mathrm{~m}$ di atas permukaan laut. Dari bulan September 2017- bulan Pebruari 2018.

Bahan yang digunakan dalam program Pengabdian ini adalah kultivar-kultivar unggul yang telah lama dilepas dan bertahan di masyarakat Pacira (Pasir Jambu, Ciwidey dan Rancabali). Adapun benihbenih yang sudah lama dibudidayakan masyarakat petani stroberi adalah empat varietas stroberi (California, Earlybrite, Sweet Charly, Santung), polibeg, media tanah dan kompos, kompos mempergunakan produk mikroorganisme lokal , NPK mutiara.

Alat yang digunakan adalah colour chart RHS. cangkul, kored, emrat, pisau, gunting stek, alat tulis, kamera, sigmameter/jangka sorong. 
Gambar 1. Colour Chart RHS

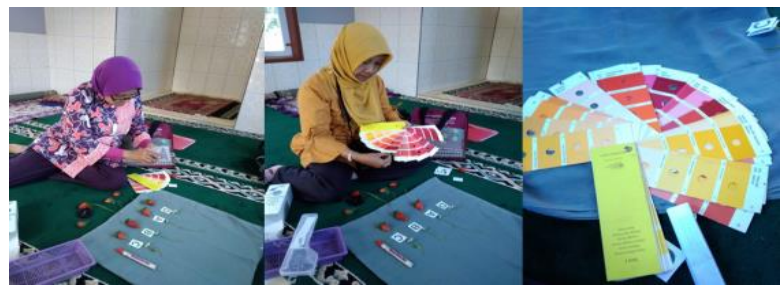

Pelaksanaan dengan metode FGD dan praktek budidaya yang dilaksanakan di Rumah Kasa (Screenhouse). Identifikasi deskriptif menggunakan empat varietas stroberi yaitu $: \mathrm{A}=$ California; $\mathrm{B}=$ Earlybrite; $\mathrm{C}=$ Sweet Charly; $\mathrm{D}=$ Santung Adapun pengamatan yang dilaksanakan adalah pengamatan secara deskriptif berdasarkan tabel UPOV.

\section{HASIL DAN PEMBAHASAN}

Tanaman stroberiyang diperbanyak secara vegetatif (dalam hal ini stroberi) mempunyai populasi yang anggotanya cenderung secara genetik seragam. Hal ini terjadi karena kemungkinan para petani memperoleh benih dengan cara menggunakan sulur tanaman dari tanaman yang sudah ada. Sumber keragaman terbesar adalah adanya persilangan dan mutasi alami. Tetap dipertahankannya suatu kultivar dalam jangka waktu lama oleh petani pada wilayah tertentu, dibandingkan dengan kultivar lain yang sudah tidak ditanam lagi menunjukkan bahwa pada kultivar tersebut terdapat gen yang memberikan keuntungan misal tahan terhadap hama atau penyakit yang pernah mewabah di wilayah tersebut. Sifat dan ketahanan buah stroberi untuk setiap varietas berbeda-beda (Luvi Harmayanvi Harahap, Saiful Bahri Daulay dan Delima Lailan Sari Nasution, 2018).

Setelah melakukan eksplorasi tahapan berikutnya adalah inventarisasi dan evaluasi terhadap bahan-bahan hasil eksplorasi, sehingga kita bisa membandingkan ekspresi gen-gen antar varietas/jenis stroberi yang kita amati. Sifat-sifat diamati berdasarkan tabel UPOV seperti terlihat pada Tabel 1 .

Tabel 1. Karakteristik Strawberi berdasarkan tabel UPOV (Union for the Protection of New Varieties of Plant) Geneva.

\begin{tabular}{|c|c|c|c|c|c|}
\hline NO & KARAKTERISTIK & A (CALIFORNIA) & B (EARLY BRITE) & $\begin{array}{l}\text { C (SWEET } \\
\text { CHARLY) }\end{array}$ & $\begin{array}{c}\text { D } \\
\text { (SANTUNG) }\end{array}$ \\
\hline 1 & Habitus Pertumbuhan & spreading(menyebar) & up-right (ke-atas) & $\begin{array}{l}\text { up-right }(\mathrm{ke}- \\
\text { atas })\end{array}$ & $\begin{array}{l}\text { up-right (ke- } \\
\text { atas) }\end{array}$ \\
\hline 2 & Kepadatan Daun & medium & padat & medium & medium \\
\hline 3 & Vigor Tanaman & sedang & kuat & sedang & sedang \\
\hline 4 & $\begin{array}{l}\text { Posisi Bunga dibandingkan dengan } \\
\text { Daun }\end{array}$ & selevel & di bawah & di bawah & di bawah \\
\hline 5 & Jumlah Stolon & medium & medium & sedikit & medium \\
\hline 6 & Warna antosianin pada Stolon & medium & medium & medium & lemah \\
\hline 7 & kepadatan Pubescens pada Stolon & medium & medium & sedikit & padat \\
\hline 8 & Ukuran Daun & medium & medium & medium & lebar \\
\hline 9 & Warna Permukaan Daun & hijau terang & hijau gelap & hijau gelap & hijau gelap \\
\hline 10 & Gerigi Tepi Daun & kuat & lemah & medium & medium \\
\hline 11 & Kilau Daun & kuat & sedang & sedang & sedang \\
\hline 12 & Keragaman Daun & tidak ada & tidak ada & tidak ada & tidak ada \\
\hline 13 & Daun terminal: Panjang ke Lebar & sama & lebih panjang & lebih panjang & lebih panjang \\
\hline 14 & Daun terminal: Bentuk Dasar & membundar (rounded) & $\begin{array}{l}\text { membundar } \\
\text { (rounded) }\end{array}$ & $\begin{array}{l}\text { membundar } \\
\text { (rounded) }\end{array}$ & $\begin{array}{l}\text { membundar } \\
\text { (rounded) }\end{array}$ \\
\hline
\end{tabular}


Jurnal Qardhul Hasan; Media Pengabdian kepada Masyarakat p-ISSN 2442-3726 e-ISSN 2550-1143

\begin{tabular}{|c|c|c|c|c|c|}
\hline 15 & Daun terminal : Margin & melengkung (crenate) & $\begin{array}{l}\text { melengkung } \\
\text { (crenate) }\end{array}$ & $\begin{array}{c}\text { bergerigi } \\
\text { melengkung } \\
\text { (serrate to } \\
\text { crenate) }\end{array}$ & $\begin{array}{l}\text { melengkung } \\
\text { (crenate) }\end{array}$ \\
\hline 16 & Daun terminal : Bentuk melintang & cekung (concave) & cekung (concave) & $\begin{array}{c}\text { cekung } \\
\text { (concave) }\end{array}$ & $\begin{array}{c}\text { cekung } \\
\text { (concave) }\end{array}$ \\
\hline 17 & Panjang Petiol & medium & panjang & panjang & Medium \\
\hline 18 & Petiol : Letak bulu rambut & agak keluar-sejajar & agak keluar-sejajar & sejajar & Sejajar \\
\hline 19 & Stipula : warna antosianin & sangat lemah & sangat lemah & sangat lemah & sangat lemah \\
\hline 20 & Inflorescence : Jumlah Bunga & sedang & sedang & $\begin{array}{l}\text { sedikit- } \\
\text { sedang }\end{array}$ & sedang \\
\hline 21 & Pedicel : Posisi Rambut & sedikit keluar & sedikit keluar & sedikit keluar & $\begin{array}{l}\text { sedikit } \\
\text { keluar }\end{array}$ \\
\hline 22 & Diameter Bunga & medium & medium & medium & medium \\
\hline 23 & Jarak antar Kelopak Bunga & bertumpuk & bertumpuk & bersentuhan & Bebas \\
\hline 24 & Ukuran calyx dibandingkan corolla & lebih besar & lebih besar & lebih besar & lebih besar \\
\hline 25 & Benangsari & ada & ada & ada & Ada \\
\hline 26 & Petal : Panjang ke Lebar & sama & sama & sama & agak panjang \\
\hline 27 & Petal : Warna bagian atas & putih (nn155d) & putih (nn155d) & $\begin{array}{c}\text { putih } \\
\text { (nn155d) }\end{array}$ & $\begin{array}{c}\text { putih } \\
\text { (nn155d) }\end{array}$ \\
\hline 28 & Buah : Panjang ke Lebar & lebih panjang & lebih panjang & agak panjang & lebih panjang \\
\hline 29 & Ukuran Buah & medium & medium & kecil & medium \\
\hline 30 & Bentuk Buah & cordate (hati) & rhomboid & cordate (hati) & cordate \\
\hline 31 & $\begin{array}{l}\text { Buah : Perbedaan bentuk terminal } \\
\text { dan bagian buah lainnya }\end{array}$ & moderat & moderat & slight & $\begin{array}{l}\text { none or very } \\
\text { slight }\end{array}$ \\
\hline 32 & Warna buah & $42 \mathrm{~b}$ & $42 \mathrm{a}$ & $42 \mathrm{c}$ & $46 \mathrm{a}$ \\
\hline 33 & Buah : Kesempurnaan warna & jelas & jelas & $\begin{array}{c}\text { sedikit } \\
\text { sempurna }\end{array}$ & $\begin{array}{c}\text { sedikit } \\
\text { sempurna }\end{array}$ \\
\hline 34 & Buah : Kilau & kuat & kuat & medium & kuat \\
\hline 35 & Buah : Kesempurnaan permukaan & sedikit sempurna & $\begin{array}{c}\text { sempurna-sangat } \\
\text { sedikit tidak } \\
\text { sempurna }\end{array}$ & $\begin{array}{l}\text { sempurna- } \\
\text { sangat } \\
\text { sedikit tidak } \\
\text { sempurna }\end{array}$ & $\begin{array}{l}\text { sangat tidak } \\
\text { sempurna }\end{array}$ \\
\hline 36 & Buah : Lebar band tanpa bintik & medium & medium & medium & medium \\
\hline 37 & Buah : Posisi Bintik & selevel & selevel & selevel & selevel \\
\hline 38 & Buah : Posisi Calyx & selevel dengan buah & $\begin{array}{l}\text { selevel dengan } \\
\text { buah }\end{array}$ & $\begin{array}{c}\text { selevel } \\
\text { dengan buah }\end{array}$ & timbul \\
\hline 39 & Buah : Keadaan sepals & upwards & upwards & upwards & outwards \\
\hline 40 & $\begin{array}{l}\text { Buah : Diameter calyx : diameter } \\
\text { buah }\end{array}$ & lebih kecil & lebih kecil & sama & lebih lebar \\
\hline 41 & Buah : adherence of calyx & medium & medium & kuat & sangat kuat \\
\hline 42 & Buah : Kulit permukaan & lunak & lunak & medium & sangat kuat \\
\hline 43 & $\begin{array}{l}\text { Buah : warna daging buah di luar } \\
\text { inti }\end{array}$ & $32 \mathrm{a}$ & $34 \mathrm{a}$ & $32 \mathrm{a}$ & n45a \\
\hline 44 & Buah : warna inti & $32 \mathrm{~b}$ & $34 \mathrm{c}$ & $32 \mathrm{c}$ & $44 d$ \\
\hline 45 & Buah : rongga & kecil & besar & kecil & medium \\
\hline 46 & Waktu awal berbunga & awal & lambat & medium & awal \\
\hline 47 & Waktu awal panen & medium & lambat & cepat & medium \\
\hline 48 & Tipe Ketahanan simpan & $\begin{array}{l}\text { agak tahan lama }(1-2 \\
\text { hari) }\end{array}$ & $\begin{array}{l}\text { tahan lama }(4 \\
\text { hari) }\end{array}$ & $\begin{array}{l}\text { tidak tahan } \\
\text { lama (1 hari) }\end{array}$ & $\begin{array}{l}\text { agak tahan } \\
\text { lama (1-2 } \\
\text { hari) }\end{array}$ \\
\hline
\end{tabular}


Empat kultivar unggul yang telah lama dilepas dan bertahan di masyarakat Pacira ini telah dianggap sebagai varietas lokal dan ras-ras yang beradaptasi di lingkungan spesifik. Penghimpunan sifat-sifat morfologi yang terdapat pada empat jenis varietas di atas akan sangat bermanfaat dalam melakukan perbaikan genetik kultivar tanaman tersebut. Dalam praktek sehari-hari keragaman sifat-sifat tanaman tersebut dapat dicatat sebagai descriptor yang spesifik sesuai dengan morfologi tanaman. Dari hasil identifikasi secara morfologi tersebut di atas ternyata setiap varietas stroberi yang diamati memiliki karakteristik yang beragam. Perbedaan varietas memerlukan penanganan panen dan pasca panen yang berbeda pula. Hal ini senada dengan pendapat Luvi Harmayanvi Harahap, Saiful Bahri Daulay dan Delima Lailan Sari Nasution (2018), bahwa perbedaan varietas mengakibatkan buah stroberi yang dipanen, baik waktu maupun tingkat kesegaran dan kekerasan buah tidak sama, karenanya perlakuan yang diberikan untuk setiap varietas harus berbeda. Pengenalan Program Identifikasi tanaman stroberi ini dapat menambah wawasan bagi petani untuk menangani masalah panen dan pasca panen yang berbeda untuk setiap varietas serta dapat dijadikan acuan untuk mendapatkan varietas tetua unggul bagi pemulia dalam mendapatkan varietas unggul baru yang lebih baik.

Beberapa manfaat yang dapat diambil dari Program Pengabdian ini adalah : Petani mengenal beberapa macam varietas stroberi yang ada di Kecamatan Pasirjambu, Ciwidey dan Rancabali (Pacira). Petani mengetahui cara membedakan karakteristik morfologi tanaman stroberi berdasarkan tabel UPOV. Petani memahami bahwa setiap varietas mempunyai karakteristik morfologi yang berbeda sehingga perlu penanganan yang berbeda pula dalam hal budidaya, panen dan pasca panen. Petani mengetahui jenis varietas stroberi unggul yang dapat dijadikan bahan tetua induk sebagai sumber benih, dan bahan tetua untuk mendapatkan varietas unggul yang lebih baik dari sebelumnya.

\section{KESIMPULAN}

Terdapat keragaman sifat-sifat tanaman dari empat varietas stroberi yang diamati, sehingga petani memperoleh wawasan dalam menangani budidaya, panen dan pasca panen yang berbeda untuk setiap varietas. Selain itu perbedaan keragaman ini bisa dimanfaatkan pemulia untuk mendapatkan jenis stroberi baru unggul dari bahan tetua yang ada.

\section{UCAPAN TERIMAKASIH}

Penulis mengucapkan terimakasih dan penghargaan yang setinggi-tingginya kepada seluruh pihak yang telah membantu terlaksananya program Pengabdian kepada Masyarakat. Program ini mendapatkan dana bantuan dari Dinas Pertanian Kabupaten Bandung dan bekerjasama dengan Balai Pengawasan dan Sertifikasi Benih, Ciganitri, Kab. Bandung.

\section{DAFTAR PUSTAKA}

Abdillah Syahroni, Sri Lestari Purnamaningsih dan Lita Sutopo. 2015. Penampilan Karakter Kuantitatif dan Kualitatif serta Keberhasilan Persilangan pada Empat Varietas Stroberi (Fragaria xananassa Duch). Jurnal Produksi Tanaman Vol. 3 (5), 370-376

Gunawan, L.W. 2000. Stroberi. Penebar Swadaya, Jakarta.

I Gusti Ayu Devi Valenia Sari, Gusti Ngurah Alit Susanta Wurya dan I Putu Sudiarta. 2018. Identifikasi Penyebab penyakit Layu pada Tanaman Stroberi (Fragaria sp.) di Desa Pancasari dan Potensi Pengendaliannya dengan Mikroba Antagonis. E-Journal Agroteknologi Tropika. Vol. 7 (1) ,104112. 
Lia Amalia dan Nunung Sondari. 2017. Perlindungan Varietas Lokal Stroberi. UNWIM.

Luvi Harmayanvi Harahap, Saiful Bahri Daulay dan Delima Lailan Sari Nasution. 2018. Identifikasi Kematangan Buah Stroberi (Fragaria $x$ vescana L.) dengan Teknik Jaringan Saraf Tiruan. Jurnal Rekayasa Pangan dan Pertanian Vol 6 (3), 602-607.

Mohammad Affan Fajar Falah, Putri Yuliastuti, Risma Hanifah, Pujo Saroyo, dan Jumeri. 2018. Kualitas Buah Stroberi ( Fragaria sp. Cv. Holibert )
Segar dan Penyimpanannya dalam Lingkungan Tropis dari Kebun Ketep Magelang Jawa Tengah. Jurnal Agroindustri Vol. 8 (1), 1-10.

Muhammad Jusuf. 2014. Plasmanutfah. Pusat Penelitian Bioteknologi, Institut Pertanian Bogor.

Rizky Ramadani Dwi Utami, Dedy Wirawan Soedibyo, Dian Purbasari. 2018. Kajian Sifat Fisik dan Kimia Buah Stroberi berdasarkan Masa Simpan dengan Pengolahan Citra. Jurnal Agroteknologi Vol 12 (2), 138-148. 